\title{
Optimal Partial Pressure of Oxygen Affects Outcomes in Patients With Severe Traumatic Brain Injury
}

James Wiginton IV ${ }^{1}$, James Brazdzionis ${ }^{1}$, Tye Patchana ${ }^{1}$, Ryan Dorkoski ${ }^{2}$, Dan E. Miulli ${ }^{1}$, Raed Sweiss ${ }^{1}$, Margaret Rose Wacker ${ }^{3}$

1. Neurosurgery, Riverside University Health System Medical Center, Moreno Valley, USA 2. Environmental and Plant Science, Ohio University, Athens, USA 3. Neurosurgery, Arrowhead Regional Medical Center, Colton, USA

Corresponding author: James Wiginton IV, chipwiginton@me.com

\section{Abstract}

\section{Introduction}

Severe traumatic brain injury (TBI) is a leading cause of death and disability. Not all neuronal damage occurs at the time of primary injury, but rather TBI initiates a cascade of events that leads to secondary brain injury. Oxygenation is one crucial factor in maintaining brain tissue homeostasis post-injury. We performed a retrospective review of patients admitted to a single trauma center after TBI. Statistical analysis was performed to ascertain if the measured partial pressure of oxygen $\left(\mathrm{PaO}_{2}\right)$ affected overall outcome at the time of discharge from the hospital.

\section{Materials and Methods}

Statistical analysis was performed retrospectively on patients admitted with a Glasgow Coma Scale (GCS) $<8$ and a diagnosis of TBI. GCS and Glasgow Outcome Scale (GOS) were calculated from physical examination findings at the time of hospital discharge or death. Patient data were separated into two groups: those with consistently higher average $\mathrm{PaO}_{2}$ scores $\left(\geqslant 150 \mathrm{mmHg} ; \mathrm{n}=7\right.$ ) and those with lower average $\mathrm{PaO}_{2}$ scores (< $150 \mathrm{mmHg} ; \mathrm{n}=8$ ). The minimum requirement to be categorized in the consistently higher group was to have an average hospital day 1 through $5 \mathrm{PaO}_{2}$ value of $\geqslant 150 \mathrm{mmHg}$.

\section{Results}

Patients with consistent hospital Day 1 through $5 \mathrm{PaO}_{2}$ scores of $\geqslant 150 \mathrm{mmHg}$ had statistically significant higher GCS scores at the end of intensive care unit (ICU)-level care or hospital discharge (mean = $12, p=0.01$ ), compared to those in group 2 with lower $\mathrm{PaO}_{2}$ levels (mean $=7.9$ ). There was no statistically significant difference in GOS when comparing the two groups ( $p=0.055)$; however, the data did show a trend toward significance.

Received 02/27/2020 Review began 03/13/2020 Review ended 08/18/2020 Published 08/23/2020

\section{(c) Copyright 2020}

Wiginton et al. This is an open access article distributed under the terms of the Creative Commons Attribution License CC-BY 4.0., which permits unrestricted use, distribution, and reproduction in any medium, provided the original author and source are credited.

\section{Discussion and Conclusion}

In our study we analyzed patients diagnosed with TBI and stratified them into groups based on $\mathrm{PaO}_{2} \geqslant$ or $<$ $150 \mathrm{mmHg}$. We demonstrate overall outcome improvement based on GCS with a trend toward improved GOS. The GCS showed statistical significance in patients with $\mathrm{PaO}_{2}$ consistently $\geqslant 150 \mathrm{mmHg}$ versus those in group 2 over the first five days of hospitalization.

Categories: Internal Medicine, Neurosurgery, Trauma

Keywords: pao2, traumatic brain injury, tbi, brain trauma, neurosurgery, partial pressure of oxygen

\section{Introduction}

Severe traumatic brain injury (TBI), defined as head injury in patients with a Glasgow Coma Scale (GCS) $\leqslant 8$, is a leading cause of death and disability that affects approximately 5.48 million individuals per year and is the cause of death for approximately 53,000 people per year $[1,2]$. In the United States alone, the incidence of closed head trauma is estimated to be 500,000 per year. Of these, $10 \%$ at admission are classified as severe (GCS $\leqslant 8$ ), another $10 \%$ as moderate (GCS 9-12), and the remainder as mild (GCS 13-15) [3]. The GCS score has been found to have a significant inverse correlation with the outcome following severe TBI. Those with a GCS of 3 had mortality rates ranging from $72 \%-78 \%$, and those with a score of 8 had a mortality of $11 \%-13 \%$ $[4,5]$. In addition to GCS and patient morbidity/mortality, the Glasgow Outcome Scale (GOS) is a widely accepted method to compare patient outcomes for those with severe TBI [4]. The GOS ranges from scores of 1 to 5: death, persistent vegetative state (PVS), severe disability (SD) (conscious but disabled), moderate disability (MD) (disabled but independent), and good recovery (GR) [6]. The GOS is determined at the end of care to best assess patient recovery and any persistent deficits as a result of neuronal damage. 
Not all neuronal damage occurs at the time of primary injury, but rather TBI initiates a cascade of events that leads to secondary brain injury [7]. Secondary brain injuries are damaging events that begin immediately after the primary impact and worsen the healing of the injured brain. Oxygenation is one crucial factor in maintaining brain tissue homeostasis post-injury. Oxygen regulation is necessary for proper mitochondrial function in aerobic glycolysis, staving off glutamate neurotoxicity, and preventing the damaging effects of reactive oxygen species [8]. Further, hyperoxemia can induce cerebral vasoconstriction causing further ischemia and injury [9].

Increased mortality and worsened short-term functional outcomes have been associated with hyperoxia within the first 24 hours of hospitalization after TBI [10]. However, strict avoidance of hyperoxemia may lead to hypoxia, and post-TBI hypoxia is associated with prolonged neuroinflammation and poor outcome. Patients with documented hypoxia $\left(\mathrm{O}_{2}\right.$ saturations $\left.<60 \%\right)$ had a mortality rate of $50 \%$, and survivors were severely disabled $[11,12]$.

Therefore, optimizing management after the primary injury can prevent further damage and improve overall outcome. Management entails close observation, typically in the intensive care unit (ICU), and requires intubation for airway protection and artificial respiration as needed. At a minimum, arterial blood gas (ABG) analysis should be performed daily with modulation of respiratory values to optimize the patient's overall medical condition and to positively influence recovery and survival. Determining the optimal partial pressure of oxygen $\left(\mathrm{PaO}_{2}\right)$ may improve outcomes in patients with severe TBI to reduce the damage from both hyperoxemia and hypoxia.

Here we perform a retrospective review of patients admitted to a single trauma center after TBI who required intubation and subsequent monitoring in the ICU. Analysis of their ABGs was performed to ascertain if the measured $\mathrm{PaO}_{2}$ affected overall outcome at the time of discharge from the hospital or end of medical care.

\section{Materials And Methods Study design}

Institutional review board approval was obtained. Patients' charts who had been admitted to Arrowhead Regional Medical Center (Colton, California) were reviewed using retrospective cohort study.

\section{Study population}

Eligible patients presented to Arrowhead Regional Medical Center with the diagnosis of severe TBI as defined by GCS $\leqslant 8$. Age was $\geqslant 18$. Patients were excluded if inciting trauma included lung trauma or previous diagnosis of asthma or chronic obstructive pulmonary disease (COPD).

\section{Data sources}

Various sources of data were used. These databases include the Arrowhead Regional Medical Center Neurosurgery Registry, electronic medical records, and scanned medical records.

\section{Data abstracted}

The following was abstracted from the above-described data sources: patient demographics including age and sex, past medical history, and clinical examination findings including presenting GCS and posttreatment GCS admission date, days in the ICU, and days until discharge or death. The GOS was calculated from physical examination findings at the time of discharge or death. Laboratory and monitoring data were obtained and included $\mathrm{PaO}_{2}$.

\section{Statistical analysis}

Statistical analysis and plot construction were done using Microsoft Excel (2016) with the Analysis ToolPak, (Microsoft Corporation, Redmond, Washington). Patient data were separated into two groups: those with consistently higher $\mathrm{PaO}_{2}$ scores ( $\left.\geqslant 150 \mathrm{mmHg} ; \mathrm{n}=7\right)$ and those with consistently lower $\mathrm{PaO}_{2}$ scores $(<150$ $\mathrm{mmHg} ; \mathrm{n}=8$ ). The minimum requirement to be categorized in the consistently higher group was to have an average hospital Day 1 through $5 \mathrm{PaO}_{2}$ value of $\geqslant 150 \mathrm{mmHg}$ (this calculation includes both minimum and maximum values). Those categorized in the consistently lower $\mathrm{PaO}_{2}$ group conversely had average hospital Day 1 through $5 \mathrm{PaO}_{2}$ values of $<150 \mathrm{mmHg}$. Student's t-test was used to find potential statistical differences between groups, including correlation with GCS on presentation and discharge/end of medical care GCS and GOS.

\section{Results}

A total of 15 patients were included in the study population from 2017 to 2019. Average GCS on arrival was 5 and at the time of discharge was 9.8 (discharge GCS ranging from 3T to 15) ("T" denotes patients with endotracheal tube or tracheostomy in place). The average GOS was 2.9. Average days in the ICU were 32.7, 


\section{Cureus}

and average days from admission until discharge or death were 33.8 .

Analysis was performed to ascertain optimal average $\mathrm{PaO}_{2}$ for the cohort that corresponded with those patients who had a high GOS (given high GOS corresponding with better clinical outcome). It was found that a $\mathrm{PaO}_{2}$ value of $\geqslant 150 \mathrm{mmHg}$ during day 1 through 5 correlated with a statically significantly higher GCS at discharge or death compared to patients with a day 1 through 5 average $\mathrm{PaO}_{2}$ of $<150 \mathrm{mmHg}(p<0.01)$.

Patient data (15 patients, labeled A-O) were separated into those with consistently high $\mathrm{PaO}_{2} \mathrm{~S}(\geqslant 150$ $\mathrm{mmHg}$; patients A, D, F, H, K, J, and L) compared to those with consistently lower $\mathrm{PaO}_{2}$ scores $(<150 \mathrm{mmHg}$; patients $\mathrm{N}, \mathrm{G}, \mathrm{C}, \mathrm{E}, \mathrm{B}, \mathrm{I}, \mathrm{O}$, and $\mathrm{M}$ ) (Table 1). The minimum requirement to be included into the consistently high $\mathrm{PaO}_{2}$ group was having an average $\geqslant 150 \mathrm{mmHg} \mathrm{PaO}_{2}$ for hospital Days 1 through 5 . There were seven patients in the consistently high $\mathrm{PaO}_{2}$ category (top of Table 1 ) and eight patients in the consistently low $\mathrm{PaO}_{2}$ category (bottom of Table 1). Initial and discharge GCS as well as GOS data are displayed in Table 2. Graphical display of the data tabulated for each patient A through $\mathrm{O}$ is shown in the Appendix.

\begin{tabular}{|c|c|c|c|c|c|c|c|c|c|c|c|}
\hline \multirow[b]{2}{*}{ Group } & \multirow[b]{2}{*}{ Patient } & \multicolumn{2}{|c|}{ Day $1 \mathrm{PaO} 2$} & \multicolumn{2}{|c|}{ Day 2 PaO2 } & \multicolumn{2}{|c|}{ Day 3 PaO2 } & \multicolumn{2}{|c|}{ Day 4 Pauz } & \multicolumn{2}{|c|}{ Day 5 Pavz } \\
\hline & & Min & Max & Min & Max & Min & Max & Min & Max & Min & Max \\
\hline & A & 70 & 115 & 135 & 151 & 187 & 204 & 137 & 193 & 151 & 165 \\
\hline & D & 150 & 243 & 150 & 195 & 139 & 175 & 139 & 179 & 183 & 191 \\
\hline & $\mathbf{F}$ & 68 & 196 & 143 & 183 & 165 & 180 & 147 & 175 & 51 & 220 \\
\hline \multirow[t]{4}{*}{ Consistently High PaO2 (>150 mmHg) } & $\mathrm{H}$ & 124 & 387 & 156 & 167 & 139 & 139 & 117 & 151 & 129 & 130 \\
\hline & $\mathrm{K}$ & 167 & 167 & 97 & 216 & 142 & 142 & 174 & 224 & 168 & 168 \\
\hline & $\mathrm{J}$ & 226 & 278 & 186 & 236 & 236 & 236 & 50 & (1 & 63 & 110 \\
\hline & $\mathrm{L}$ & 204 & 206 & 155 & 252 & 150 & 154 & 146 & 146 & 163 & 163 \\
\hline \multirow{8}{*}{ Consistently Low PaO2 (<150 mmHg) } & B & 106 & 163 & 134 & 134 & 145 & 145 & 110 & 146 & 82 & 101 \\
\hline & C & 99 & 128 & 81 & 97 & 99 & 151 & 66 & 203 & 132 & 132 \\
\hline & E & 153 & 153 & 113 & 113 & 111 & 111 & 105 & 105 & 113 & 144 \\
\hline & G & 116 & 116 & 85 & 112 & 77 & 144 & 57 & 72 & 64 & 165 \\
\hline & 1 & 108 & 108 & 144 & 195 & 94 & 108 & 133 & 145 & 105 & 136 \\
\hline & $\mathrm{M}$ & 128 & 128 & 137 & 165 & 155 & 186 & 176 & 176 & 107 & 107 \\
\hline & $\mathrm{N}$ & 141 & 182 & 88 & 88 & 72 & 72 & 83 & 83 & 85 & 85 \\
\hline & 0 & 155 & 155 & 116 & 116 & 139 & 139 & 95 & 151 & 133 & 150 \\
\hline \multicolumn{11}{|c|}{ TABLE 1: Comparison of $\mathrm{PaO}_{2}$ values of patients with consistently high $\mathrm{PaO}_{2}$ versus those with } & Nith \\
\hline \multicolumn{12}{|l|}{ Min = minimum } \\
\hline Max = maximum & & & & & & & & & & & \\
\hline
\end{tabular}




\section{Cureus}

\begin{tabular}{|c|c|c|c|c|}
\hline Group & Patient & Presenting GCS & GCS at Discharge or End of Care & GOS \\
\hline \multirow{7}{*}{ Consistently High $\mathrm{PaO}_{2}$ (>150 mmHg) } & A & 3T & 15 & 4 \\
\hline & D & 5T & 15 & 4 \\
\hline & $\mathrm{F}$ & $6 \mathrm{~T}$ & 10T & 3 \\
\hline & $\mathrm{H}$ & 4T & 10T & 3 \\
\hline & K & 6T & 9T & 3 \\
\hline & $\mathrm{J}$ & 6T & 15 & 4 \\
\hline & L & 3T & 10T & 2 \\
\hline \multirow{9}{*}{ Consistently Low $\mathrm{PaO}_{2}(>150$ mmHg) } & B & 4T & 10T & 3 \\
\hline & C & 3T & 3T & 2 \\
\hline & E & 6T & 9 & 3 \\
\hline & G & 8T & 3 & 1 \\
\hline & 1 & $4 \mathrm{~T}$ & $6 \mathrm{~T}$ & 3 \\
\hline & $\mathrm{M}$ & 3T & $11 \mathrm{~T}$ & 3 \\
\hline & $\mathrm{N}$ & $8 \mathrm{~T}$ & $11 \mathrm{~T}$ & 3 \\
\hline & 0 & 6T & 10T & 3 \\
\hline & Average & 5.0 & 9.8 & 2.9 \\
\hline
\end{tabular}

TABLE 2: Patients presenting GCS and GCS at discharge or end of care along with GOS at discharge or end of care

"T" denotes patient with endotracheal tube or tracheostomy in place.

GCS $=$ Glasgow Coma Scale

GOS = Glasgow Outcome Scale

Those with consistent hospital day 1 through $5 \mathrm{PaO}_{2}$ scores of $\geqslant 150 \mathrm{mmHg}$ had statistically significantly higher GCS scores at the end of ICU-level care or discharge ( $p=0.01 ; 48 \%$ increase). In fact, those in the consistently high averaged $\mathrm{PaO}_{2}$ group had a mean GCS of 12 compared to GCS of 7.9 in those with lower averaged $\mathrm{PaO}_{2}$ (Figure 1). There was no statistically significant difference in GOS when comparing the two groups $(\mathrm{p}=0.055)$; however, the data did show a trend toward significance (Figure 2). 


\section{Cureus}

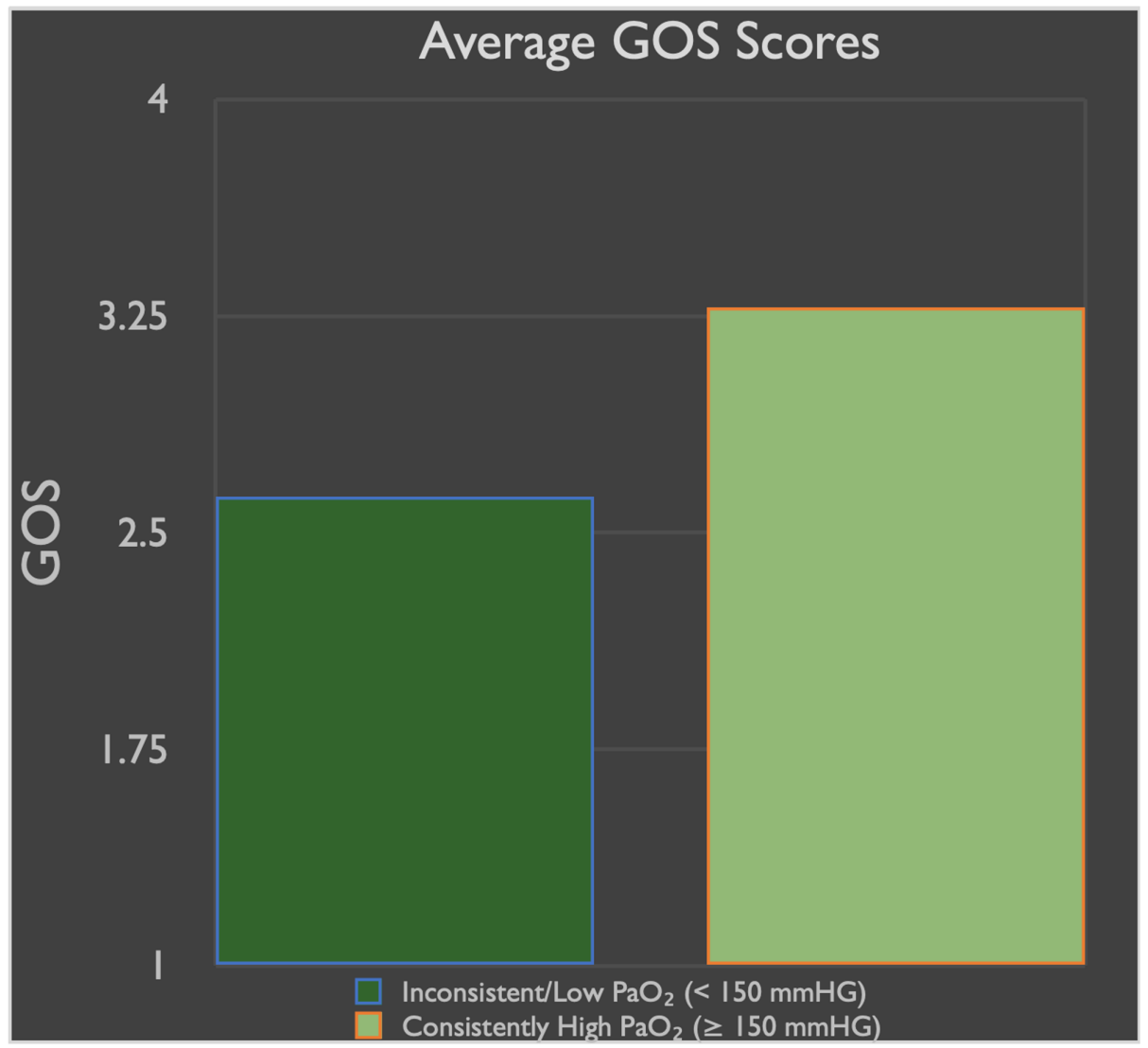

FIGURE 1: Average GOS at discharge/end of care for patients stratified into the two groups

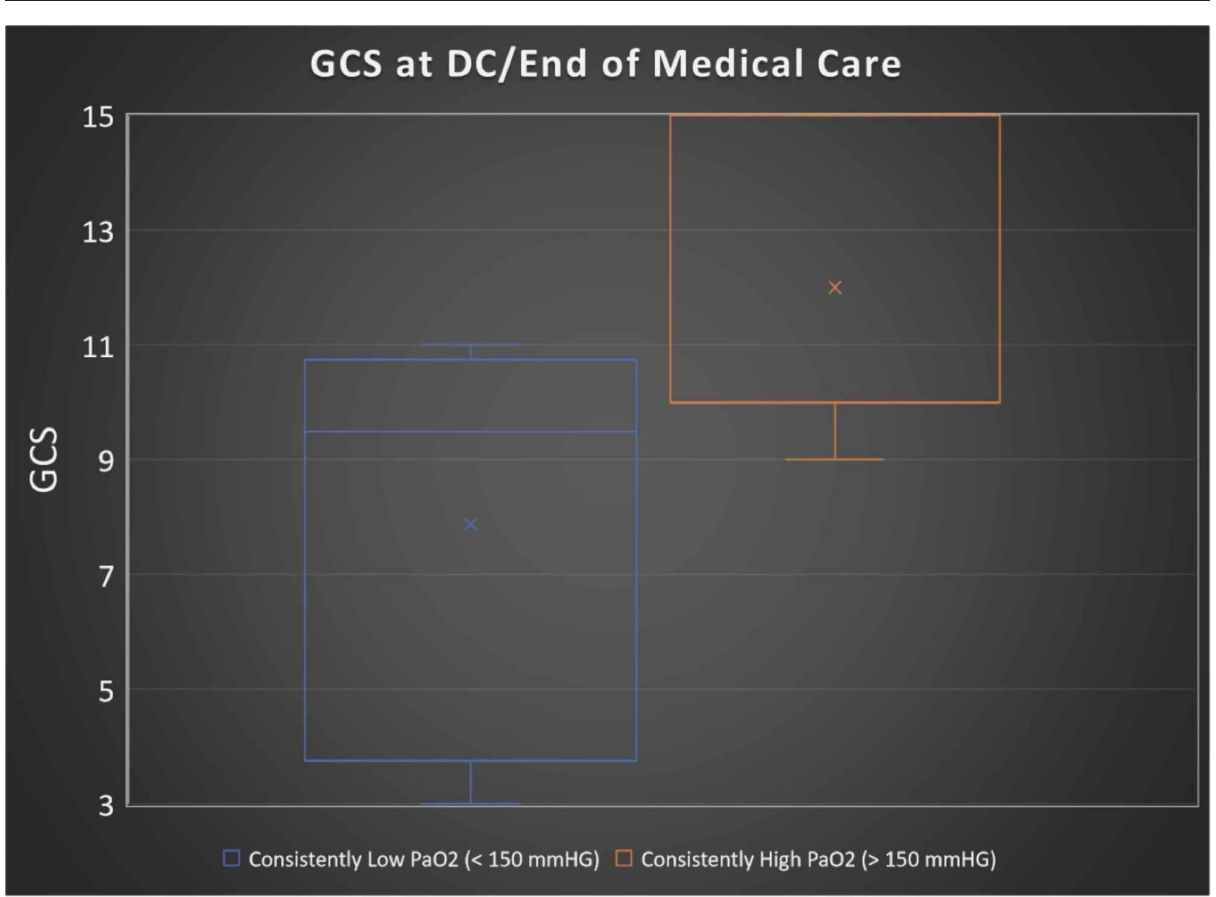

FIGURE 2: Average GCS at DC/end of care for patients stratified into the two groups

GCS = Glasgow Coma Scale

$D C$ = discharge 


\section{Discussion}

Brain oxygenation in TBI is important to optimize to minimize secondary injury and ultimately reduce morbidity and mortality. Arterial oxygenation in the blood, as measured by $\mathrm{PaO}_{2}$, must be adequate to allow proper perfusion and oxygen transport to the brain. It has been shown that hypoxia in the setting of TBI can lead to overall worse outcomes [11,12].

At our institution, we have considered a $\mathrm{PaO}_{2}$ of $>100 \mathrm{mmHg}$ as measured by arterial blood gas (ABG) to be adequate in optimizing the brain's ability to avoid secondary injury. In this study, by collecting average $\mathrm{PaO}_{2}$ data in patients diagnosed with TBI and by correlating that data with outcomes in terms of GCS and GOS, we were able to ascertain if another $\mathrm{PaO}_{2}$ value would be more beneficial.

Based on our available data and number of enrolled patients, we placed them into two separate groups established by post-hoc analysis: the first group with a consistent $\mathrm{PaO}_{2} \geqslant 150 \mathrm{mmHg}$ and the second group that had a consistent $\mathrm{PaO}_{2}<150 \mathrm{mmHg}$. Using these cutoffs we compared overall GCS and GOS to determine if stratification into these groups led to an overall improvement in outcomes, or if there were no differences.

Glasgow Outcome Scale was technically not significantly higher in patients with consistent $\mathrm{PaO}_{2} \mathrm{~S} \geqslant 150$ $\operatorname{mmHg}(p=0.055)$; however, the data showed a trend toward statistical significance and showed promising results in relation to outcome. On the other hand, a patient's GCS at the time of discharge was statistically significantly different $(p=0.01)$ in the $\mathrm{PaO}_{2} \geqslant 150 \mathrm{mmHg}$ group. The latter would indicate a level of correlation of blood oxygenation and improved outcomes in patients with TBI.

Of note, our study has limitations given the small sample size. While an optimal $\mathrm{PaO}_{2}$ of $\geqslant 150 \mathrm{mmHg}$ was found, it would be helpful to perform further research and to obtain a larger sample size. This will allow for further stratification to determine if there may be another $\mathrm{PaO}_{2}$ value that would lead to better outcomes or if over-oxygenation/hyperoxemia would actually negatively affect outcomes. Future studies may attempt to tightly titrate $\mathrm{PaO}_{2}$ to establish a stricter upper limit to reduce the risk of reactive oxygen damage. We also were unable to perform long-term follow-up for these patients and recognize that three-month or six-month follow-up would be ideal in terms of monitoring GOS.

Another potential limitation lies in the fact that patients with TBI typically have a multitude of comorbidities including concomitant injuries. While our exclusion criteria included known lung injury, COPD, and asthma, there could be other confounding variables that contribute to overall outcome of these patients, not least of which is their brain injury.

Despite these limitations, we believed it was important to focus on the individual aspect of blood oxygenation, since the ramifications of hypoxia can be especially severe. Hopefully, in the future there will be further studies into the individual and aggregate aspects of TBI and their influence on overall survival and outcome. Our results show that when focusing on oxygenation in TBI, a higher $\mathrm{PaO}_{2}$ consistently $\geqslant 150$ $\mathrm{mmHg}$ correlated with a statistically improved GCS at the time of discharge and a GOS trending toward positive significance.

\section{Conclusions}

Intracranial pressure, blood pressure optimization, cerebral oxygenation, and brain tissue oxygenation are all important areas of assessment and modulation in patients with TBI. Another important aspect is blood oxygenation whereby the brain receives this necessary component and whereby secondary injury can be mitigated. In our study we analyzed patients diagnosed with TBI and stratified them into groups based on $\mathrm{PaO}_{2}$ values $\geqslant$ or $<150 \mathrm{mmHg}$. We demonstrate overall improvement of GCS and GOS with GCS showing statistical significance in patients with $\mathrm{PaO}_{2}$ consistently $\geqslant 150 \mathrm{mmHg}$ over the first five days of hospitalization. Future studies with a larger sample size may help to better delineate specific thresholds including an upper limit and to analyze other aspects of this challenging disease.

\section{Appendices}




\section{Cureus}

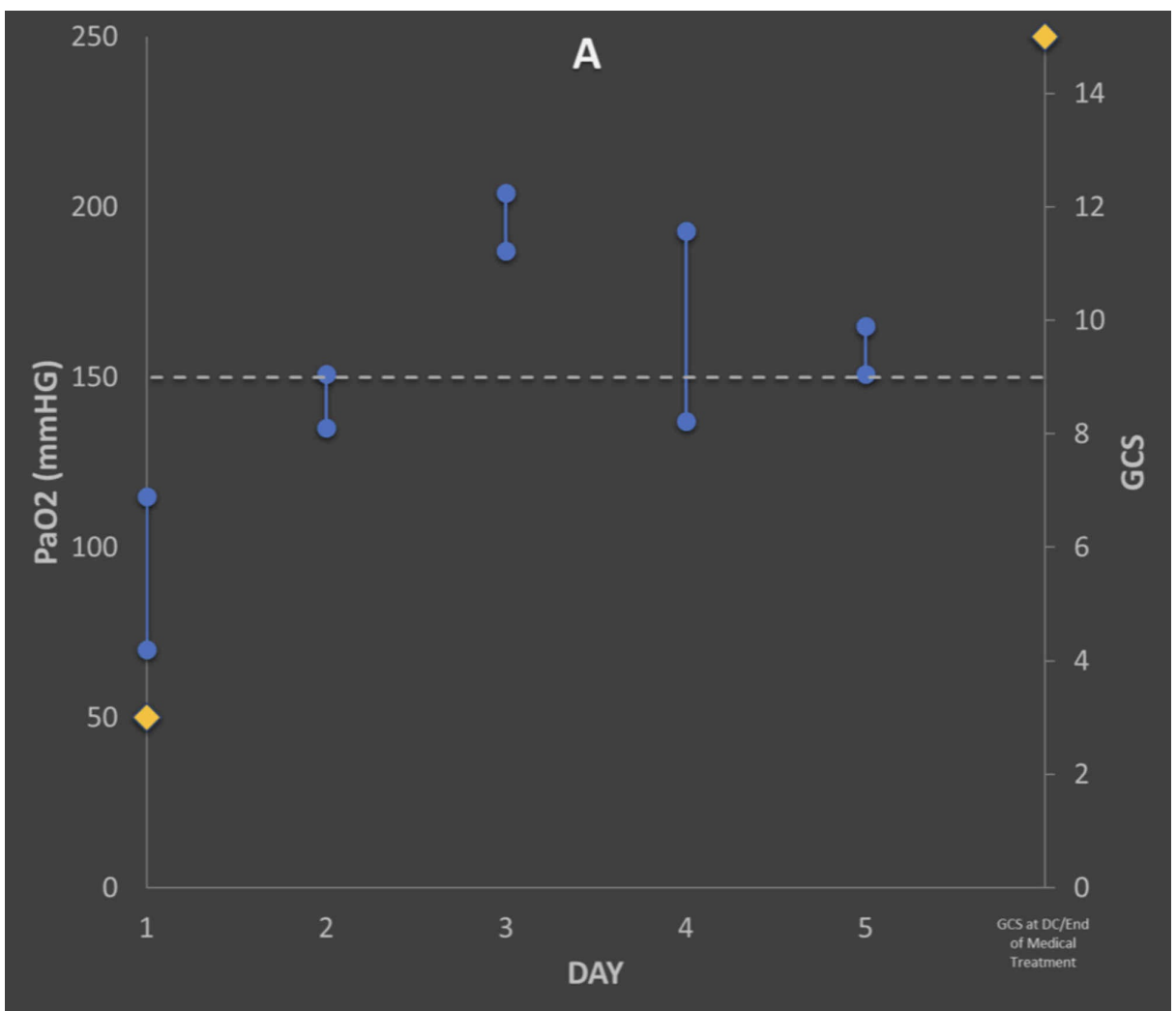

FIGURE 3: Graph for Patient A, demonstrating maximum and minimum $\mathrm{PaO}_{2}$ levels above the predefined $150 \mathrm{mmHg}$ threshold (dotted line)

GCS during the first day of monitoring and at the hospital discharge or the end of ICU-level care are demonstrated by yellow diamonds.

Partial pressure of oxygen ( $\mathrm{PaO}_{2}$ ); Glasgow Coma Scale (GCS); intensive care unit (ICU).

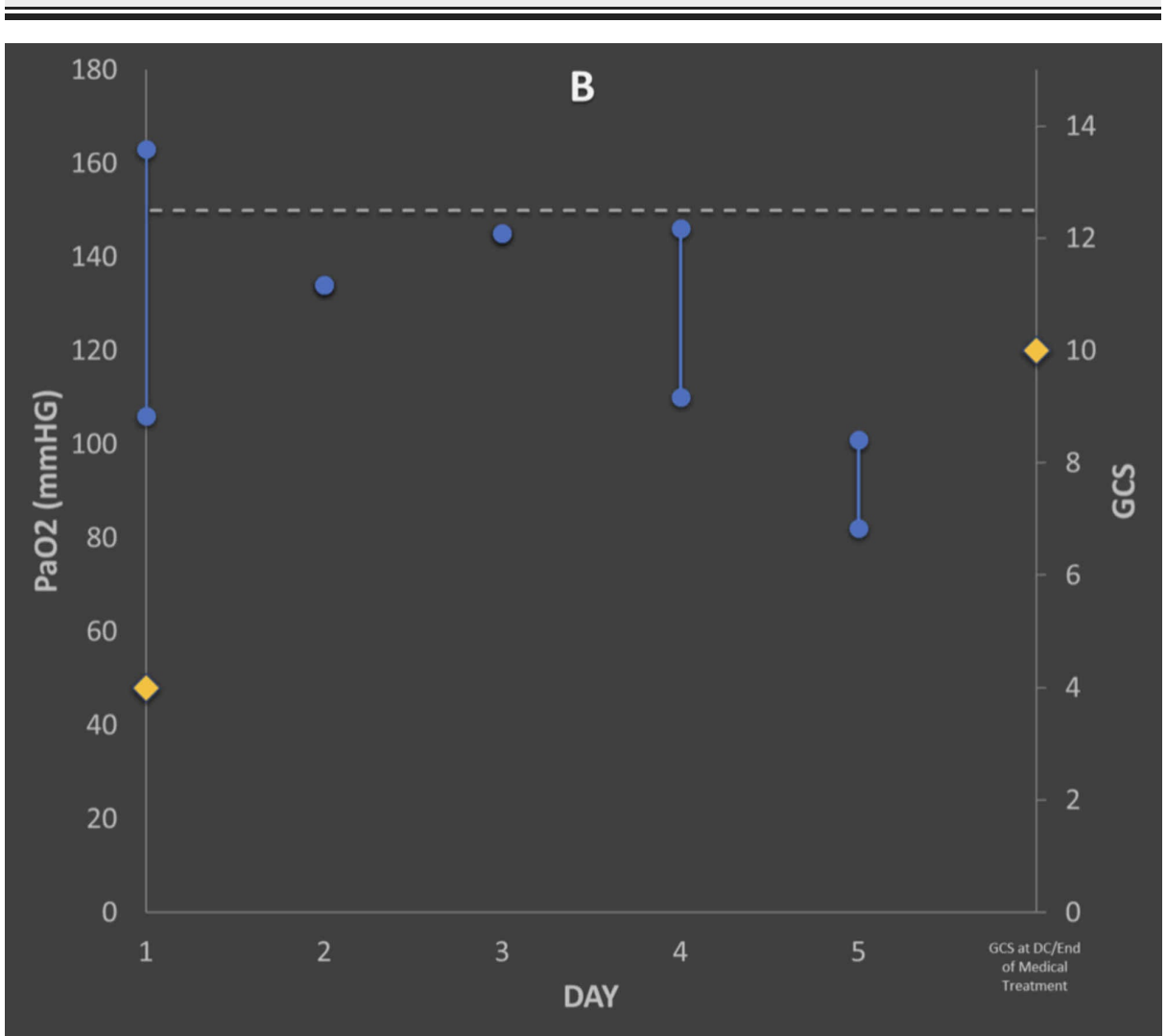




\section{Cureus}

FIGURE 4: Graph for Patient B, demonstrating maximum and minimum $\mathrm{PaO}_{2}$ levels above the predefined $150 \mathrm{mmHg}$ threshold (dotted line)

GCS during the first day of monitoring and at the hospital discharge or the end of ICU-level care are demonstrated by yellow diamonds.

Partial pressure of oxygen ( $\left.\mathrm{PaO}_{2}\right)$; Glasgow Coma Scale (GCS); intensive care unit (ICU).

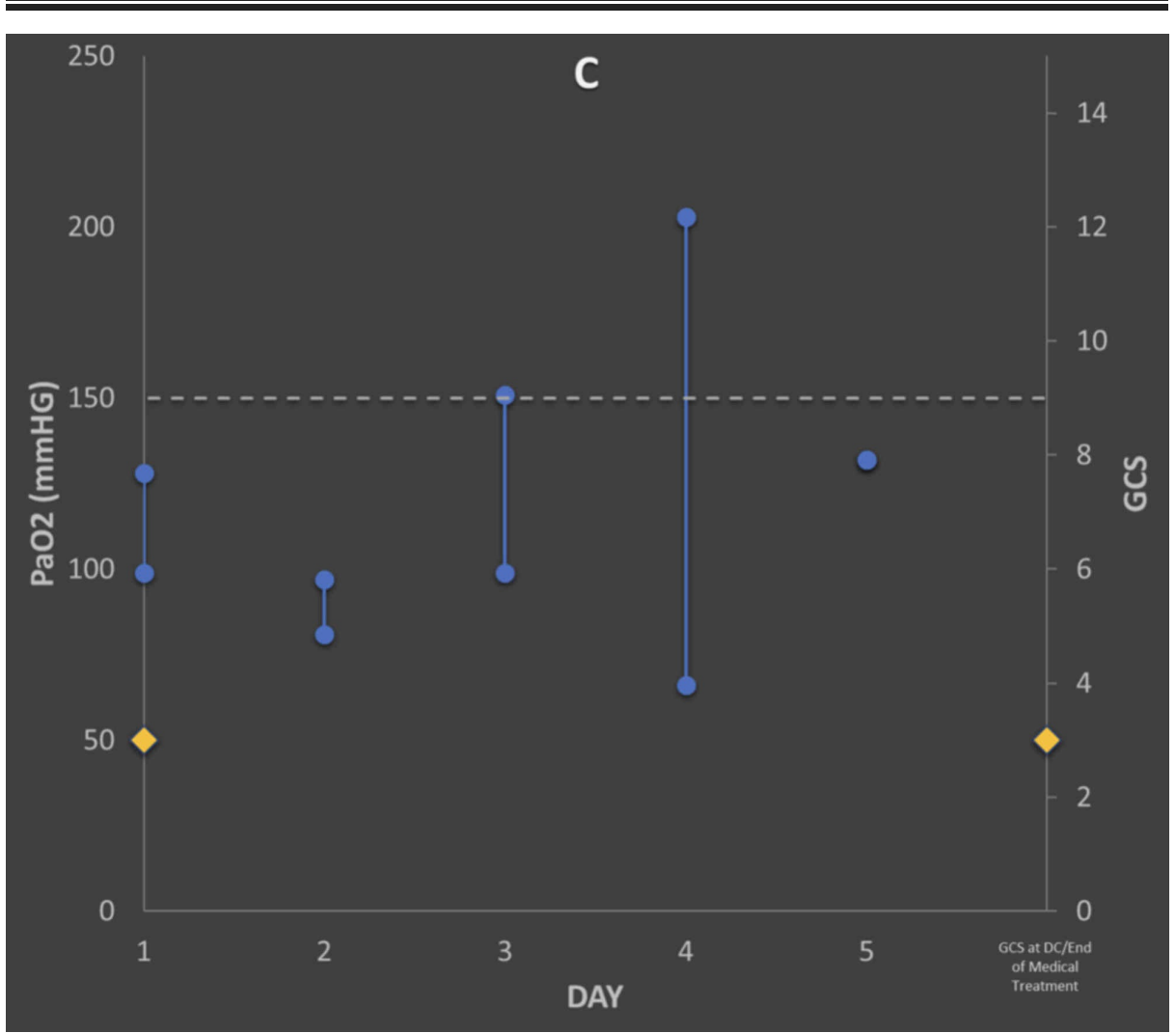

FIGURE 5: Graph for Patient C, demonstrating maximum and minimum $\mathrm{PaO}_{2}$ levels above the predefined $150 \mathrm{mmHg}$ threshold (dotted line)

GCS during the first day of monitoring and at the hospital discharge or the end of ICU-level care are demonstrated by yellow diamonds.

Partial pressure of oxygen ( $\left.\mathrm{PaO}_{2}\right)$; Glasgow Coma Scale (GCS); intensive care unit (ICU). 


\section{Cureus}

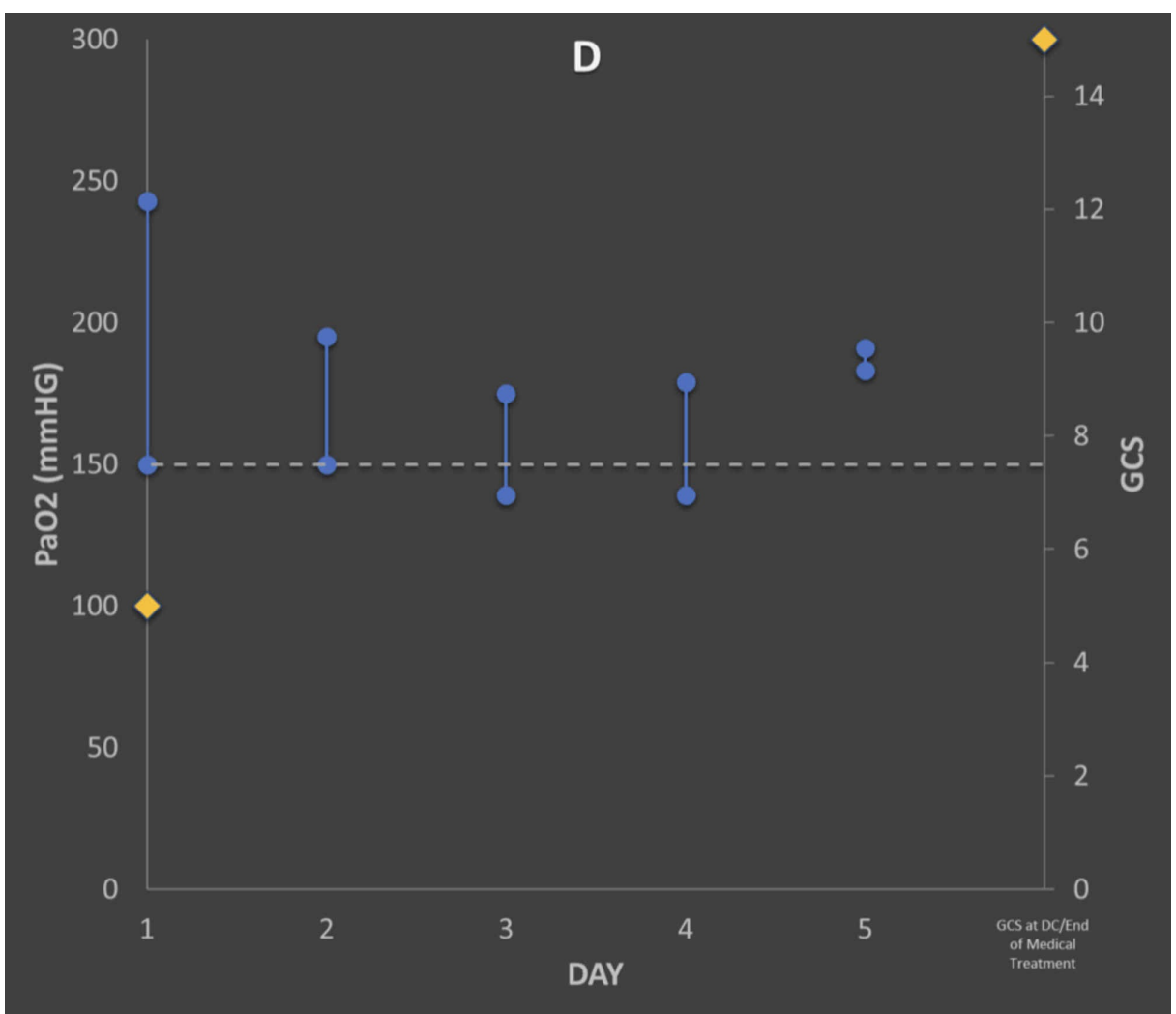

FIGURE 6: Graph for Patient D, demonstrating maximum and minimum $\mathrm{PaO}_{2}$ levels above the predefined $150 \mathrm{mmHg}$ threshold (dotted line)

GCS during the first day of monitoring and at the hospital discharge or the end of ICU-level care are demonstrated by yellow diamonds.

Partial pressure of oxygen ( $\left.\mathrm{PaO}_{2}\right)$; Glasgow Coma Scale (GCS); intensive care unit (ICU).

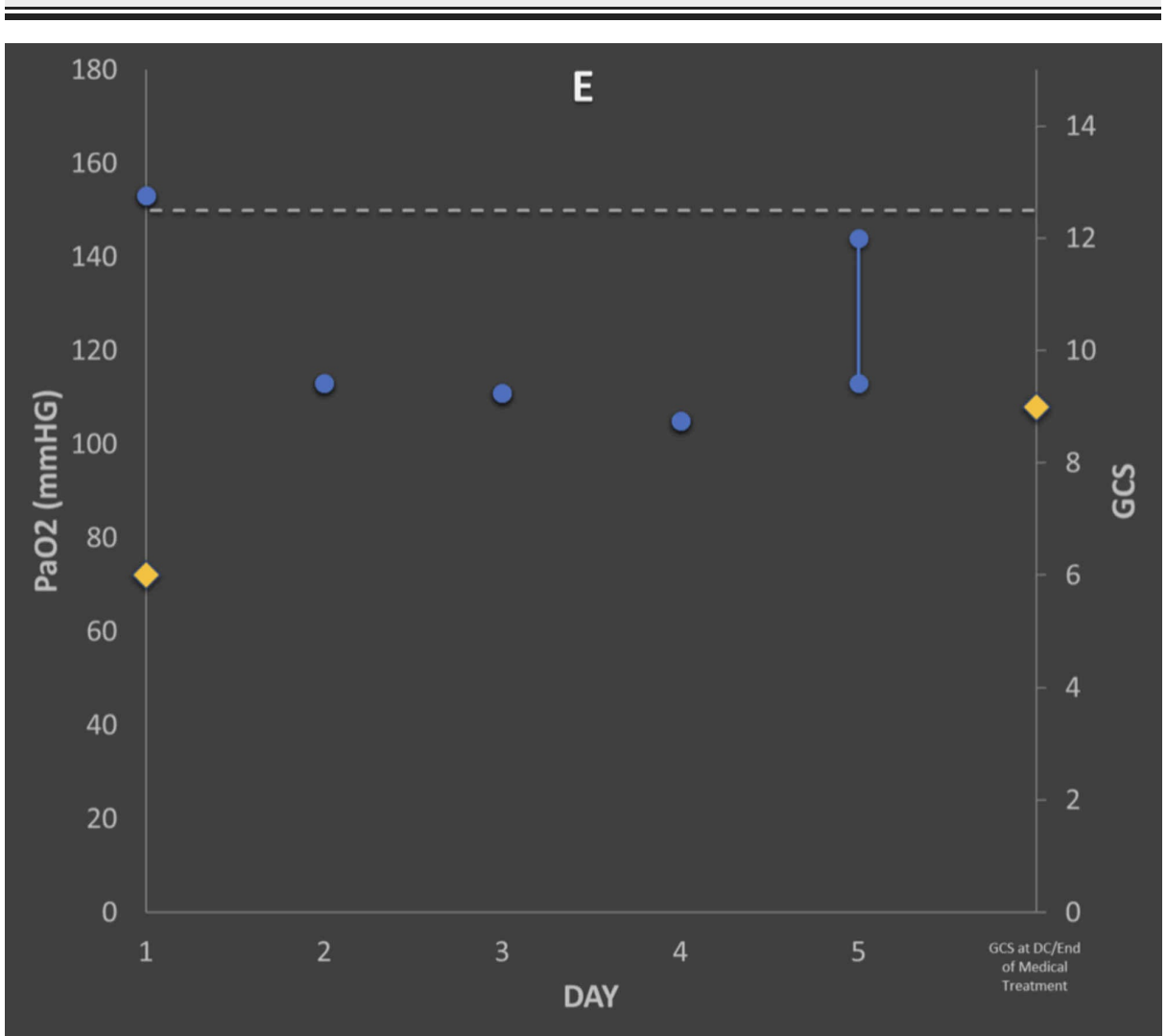




\section{Cureus}

FIGURE 7: Graph for Patient E, demonstrating maximum and minimum $\mathrm{PaO}_{2}$ levels above the predefined $150 \mathrm{mmHg}$ threshold (dotted line)

GCS during the first day of monitoring and at the hospital discharge or the end of ICU-level care are demonstrated by yellow diamonds.

Partial pressure of oxygen ( $\left.\mathrm{PaO}_{2}\right)$; Glasgow Coma Scale (GCS); intensive care unit (ICU).

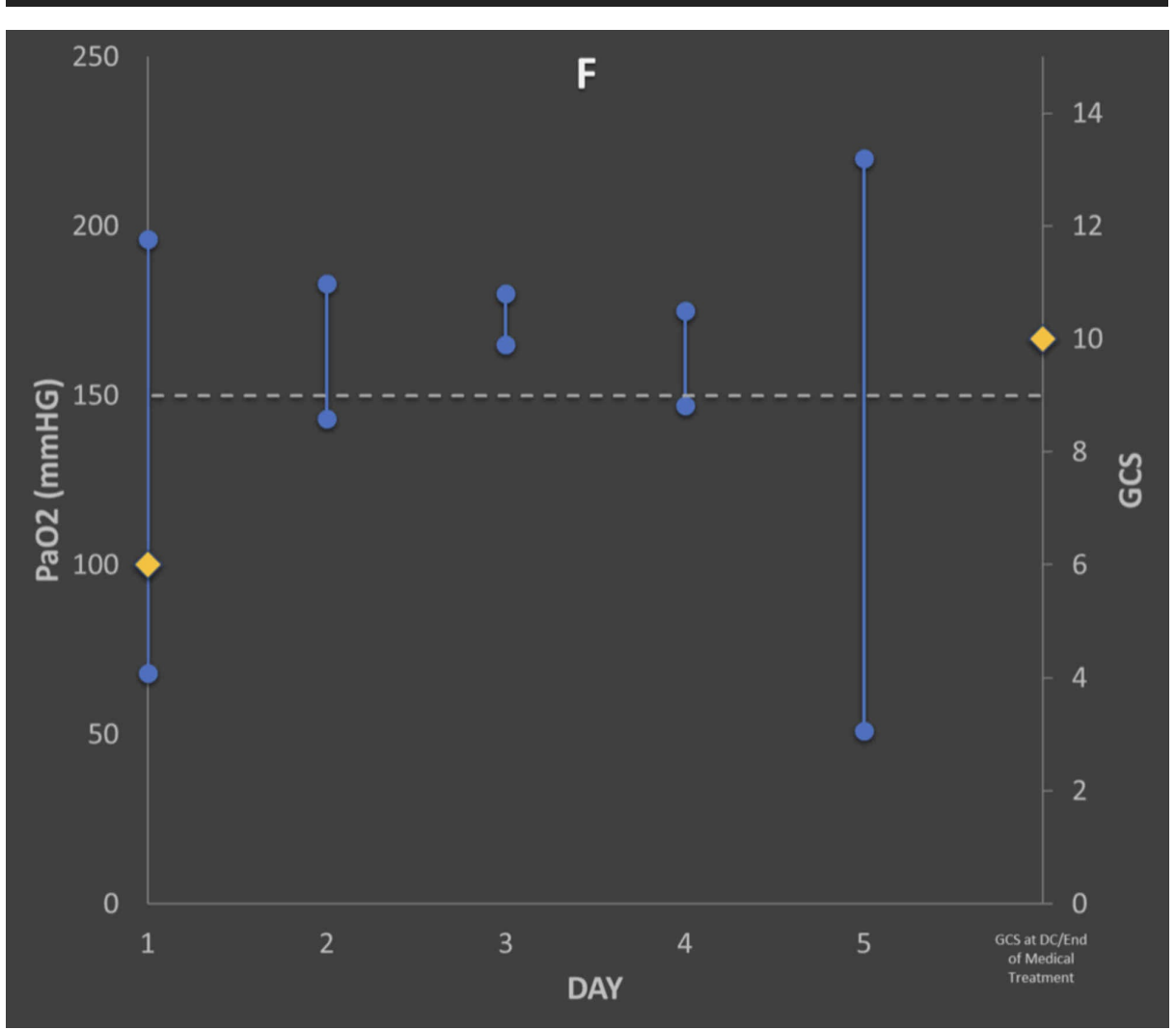

FIGURE 8: Graph for Patient F, demonstrating maximum and minimum $\mathrm{PaO}_{2}$ levels above the predefined $150 \mathrm{mmHg}$ threshold (dotted line)

GCS during the first day of monitoring and at the hospital discharge or the end of ICU-level care are demonstrated by yellow diamonds.

Partial pressure of oxygen ( $\left.\mathrm{PaO}_{2}\right)$; Glasgow Coma Scale (GCS); intensive care unit (ICU). 


\section{Cureus}

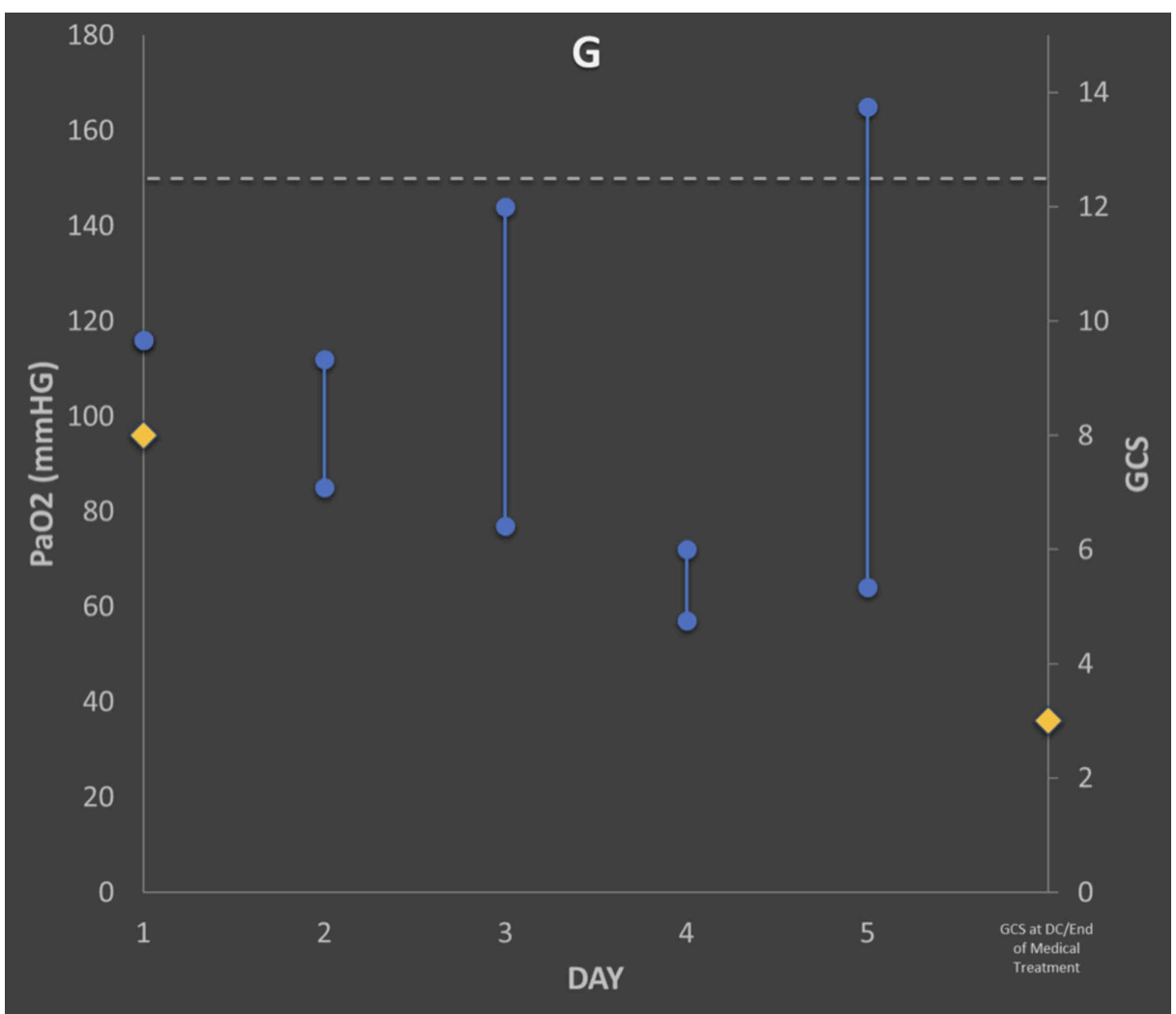

FIGURE 9: Graph for Patient G, demonstrating maximum and minimum $\mathrm{PaO}_{2}$ levels above the predefined $150 \mathrm{mmHg}$ threshold (dotted line)

GCS during the first day of monitoring and at the hospital discharge or the end of ICU-level care are demonstrated by yellow diamonds.

Partial pressure of oxygen $\left(\mathrm{PaO}_{2}\right)$; Glasgow Coma Scale (GCS); intensive care unit (ICU).

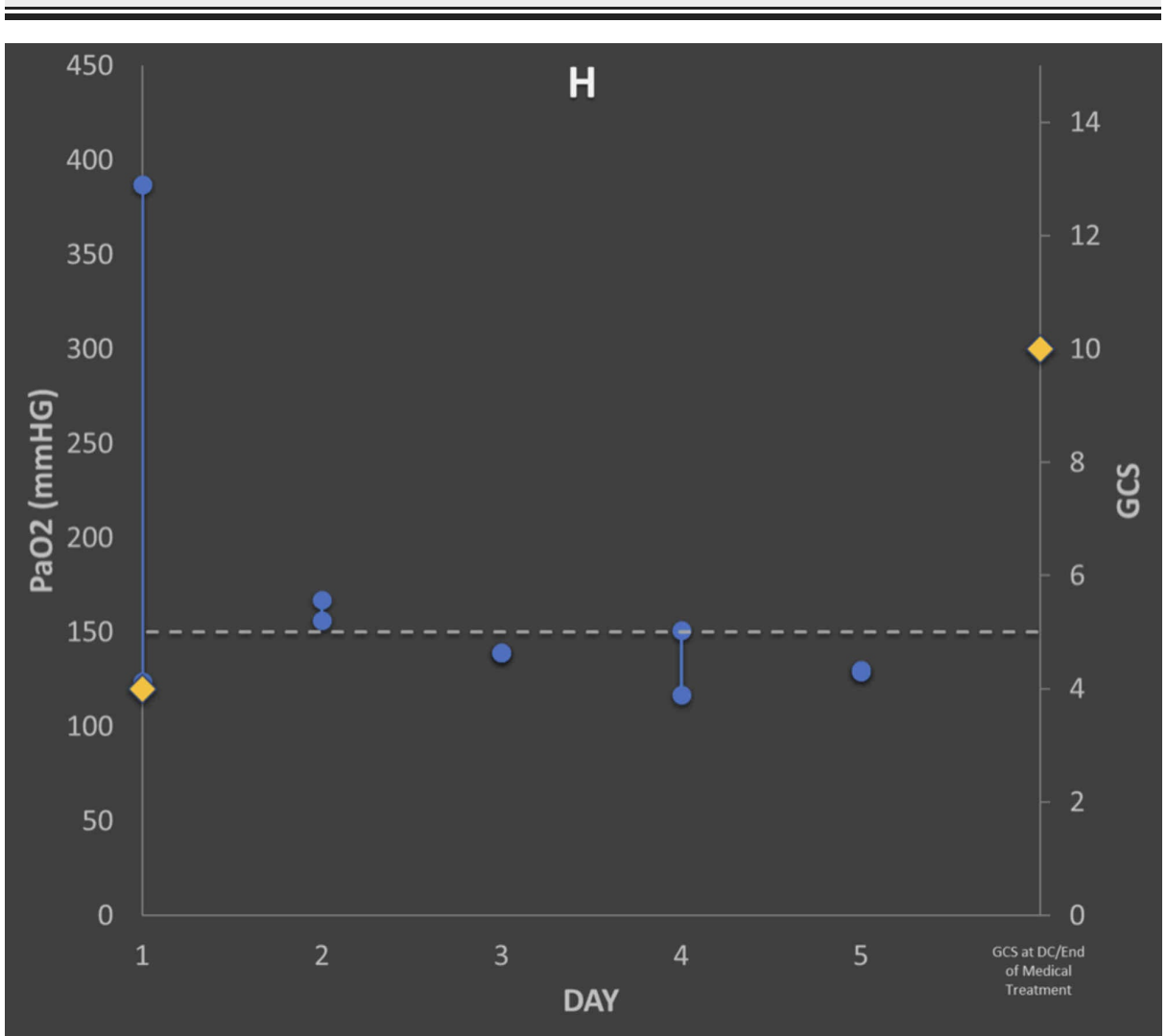




\section{Cureus}

FIGURE 10: Graph for Patient H, demonstrating maximum and minimum $\mathrm{PaO}_{2}$ levels above the predefined $150 \mathrm{mmHg}$ threshold (dotted line)

GCS during the first day of monitoring and at the hospital discharge or the end of ICU-level care are demonstrated by yellow diamonds.

Partial pressure of oxygen $\left(\mathrm{PaO}_{2}\right)$; Glasgow Coma Scale (GCS); intensive care unit (ICU).

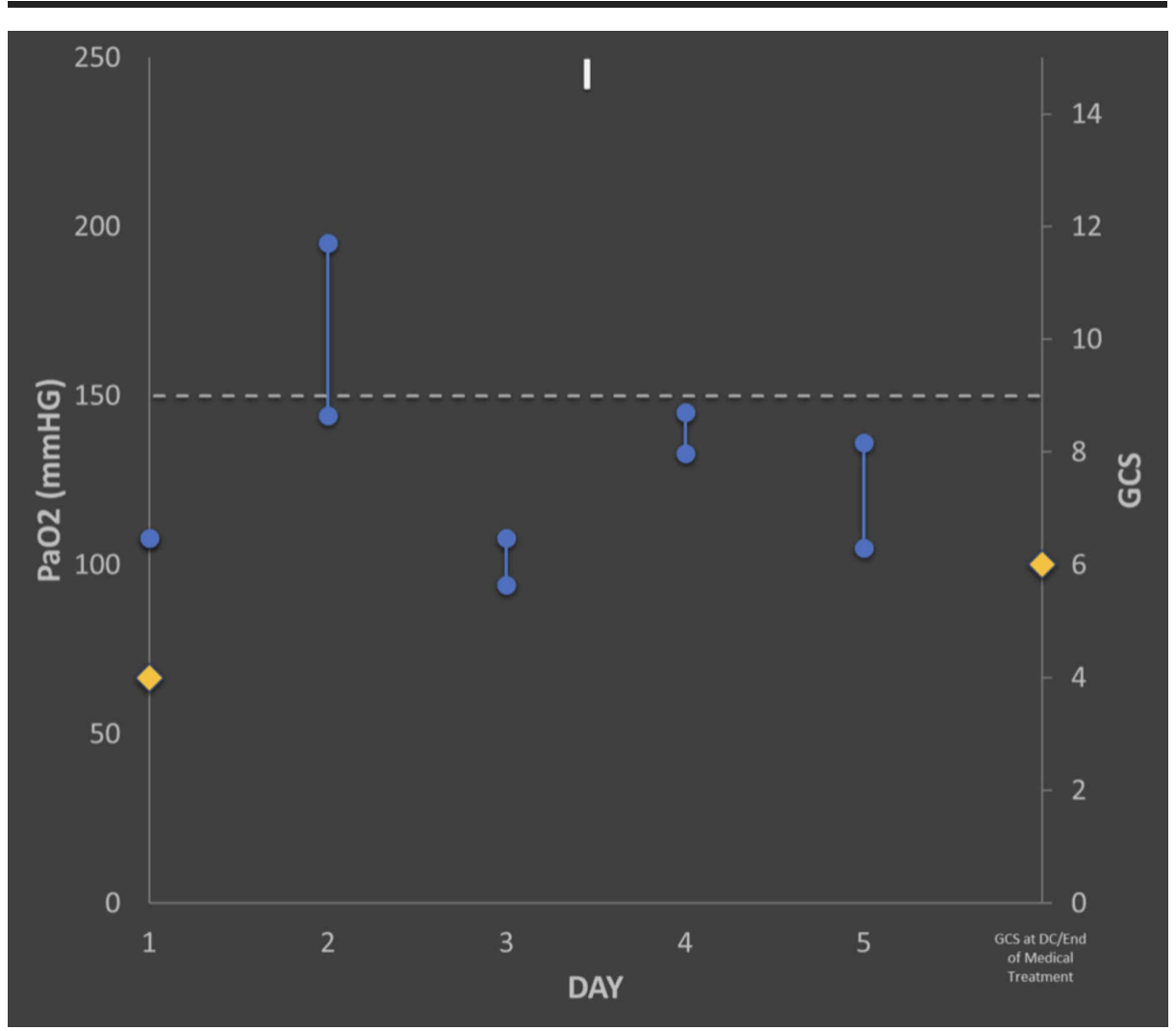

FIGURE 11: Graph for Patient I, demonstrating maximum and minimum $\mathrm{PaO}_{2}$ levels above the predefined $150 \mathrm{mmHg}$ threshold (dotted line)

GCS during the first day of monitoring and at the hospital discharge or the end of ICU-level care are demonstrated by yellow diamonds.

Partial pressure of oxygen ( $\left.\mathrm{PaO}_{2}\right)$; Glasgow Coma Scale (GCS); intensive care unit (ICU). 


\section{Cureus}

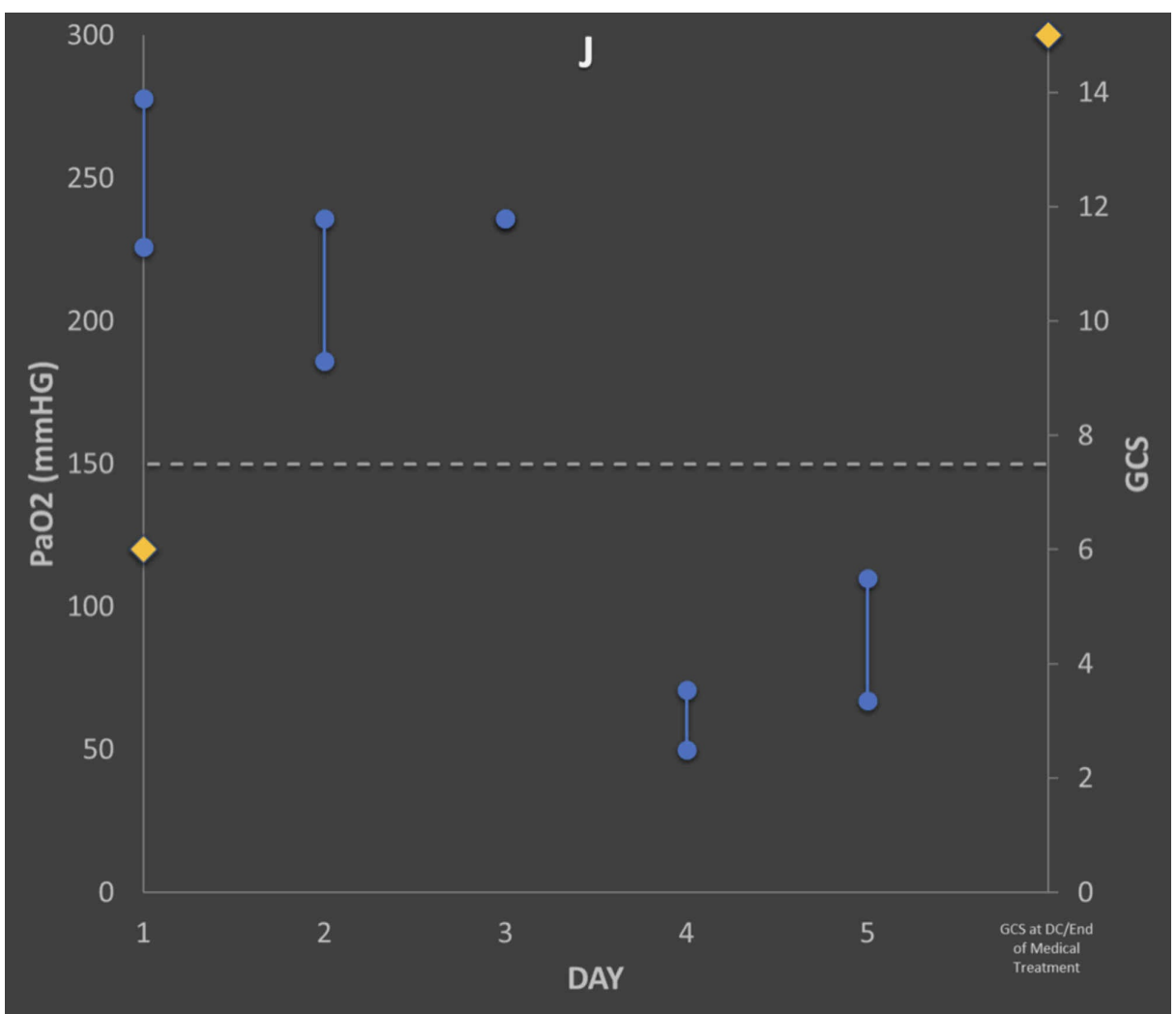

FIGURE 12: Graph for Patient J, demonstrating maximum and minimum $\mathrm{PaO}_{2}$ levels above the predefined $150 \mathrm{mmHg}$ threshold (dotted line)

GCS during the first day of monitoring and at the hospital discharge or the end of ICU-level care are demonstrated by yellow diamonds.

Partial pressure of oxygen $\left(\mathrm{PaO}_{2}\right)$; Glasgow Coma Scale (GCS); intensive care unit (ICU).

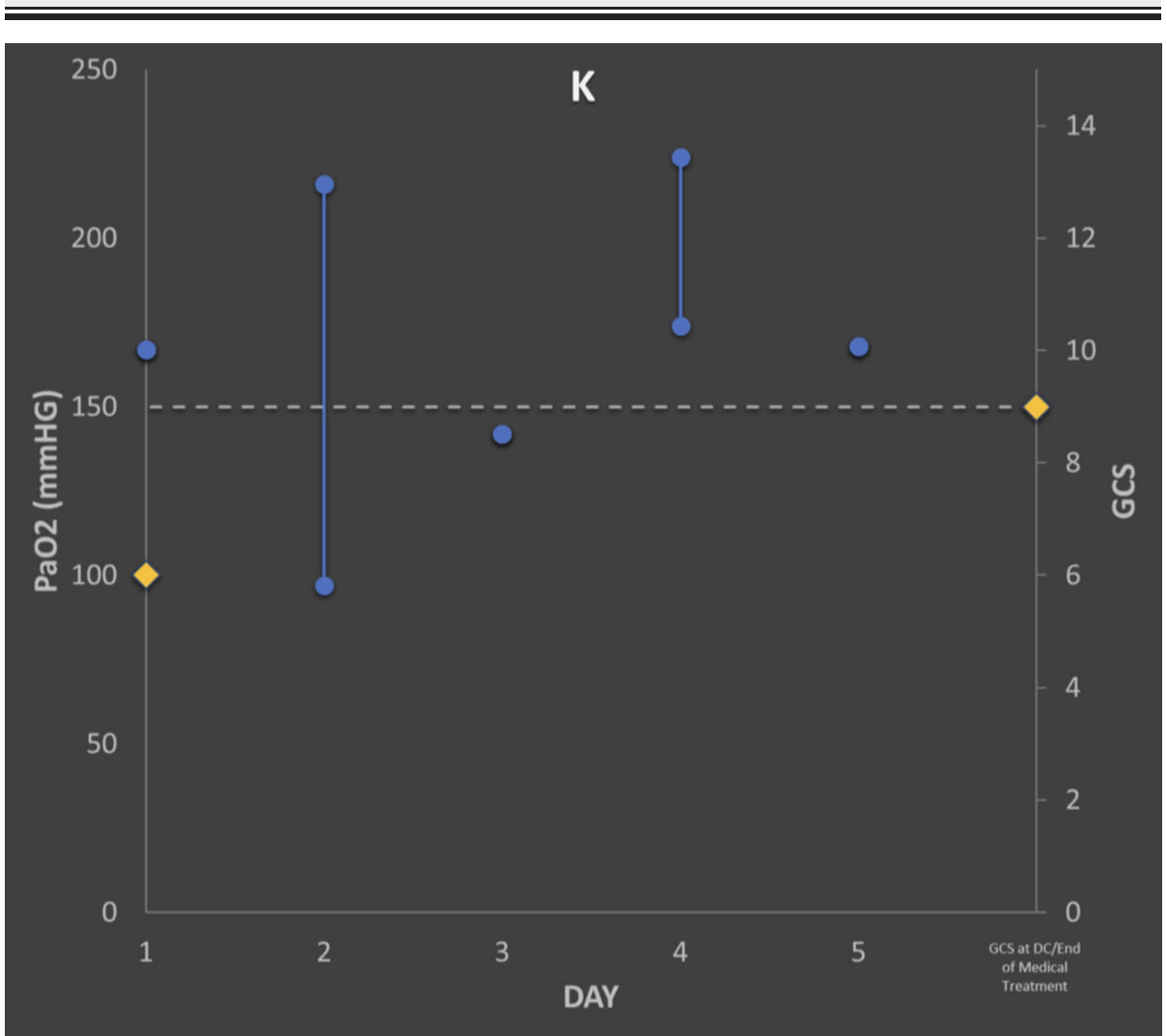




\section{Cureus}

FIGURE 13: Graph for Patient K, demonstrating maximum and minimum $\mathrm{PaO}_{2}$ levels above the predefined $150 \mathrm{mmHg}$ threshold (dotted line)

GCS during the first day of monitoring and at the hospital discharge or the end of ICU-level care are demonstrated by yellow diamonds.

Partial pressure of oxygen $\left(\mathrm{PaO}_{2}\right)$; Glasgow Coma Scale (GCS); intensive care unit (ICU).

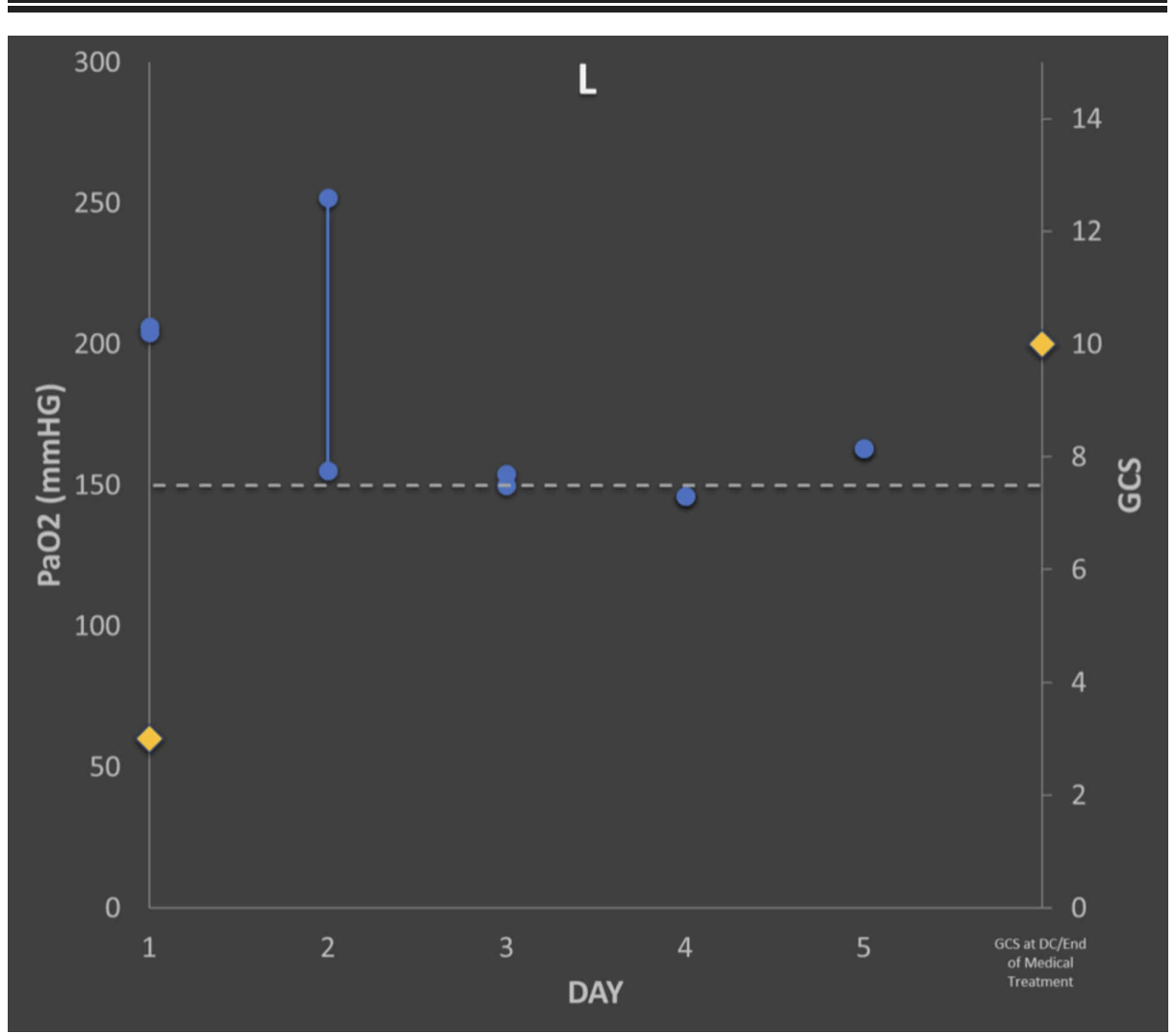

FIGURE 14: Graph for Patient L, demonstrating maximum and minimum $\mathrm{PaO}_{2}$ levels above the predefined $150 \mathrm{mmHg}$ threshold (dotted line)

GCS during the first day of monitoring and at the hospital discharge or the end of ICU-level care are demonstrated by yellow diamonds.

Partial pressure of oxygen ( $\left.\mathrm{PaO}_{2}\right)$; Glasgow Coma Scale (GCS); intensive care unit (ICU). 


\section{Cureus}

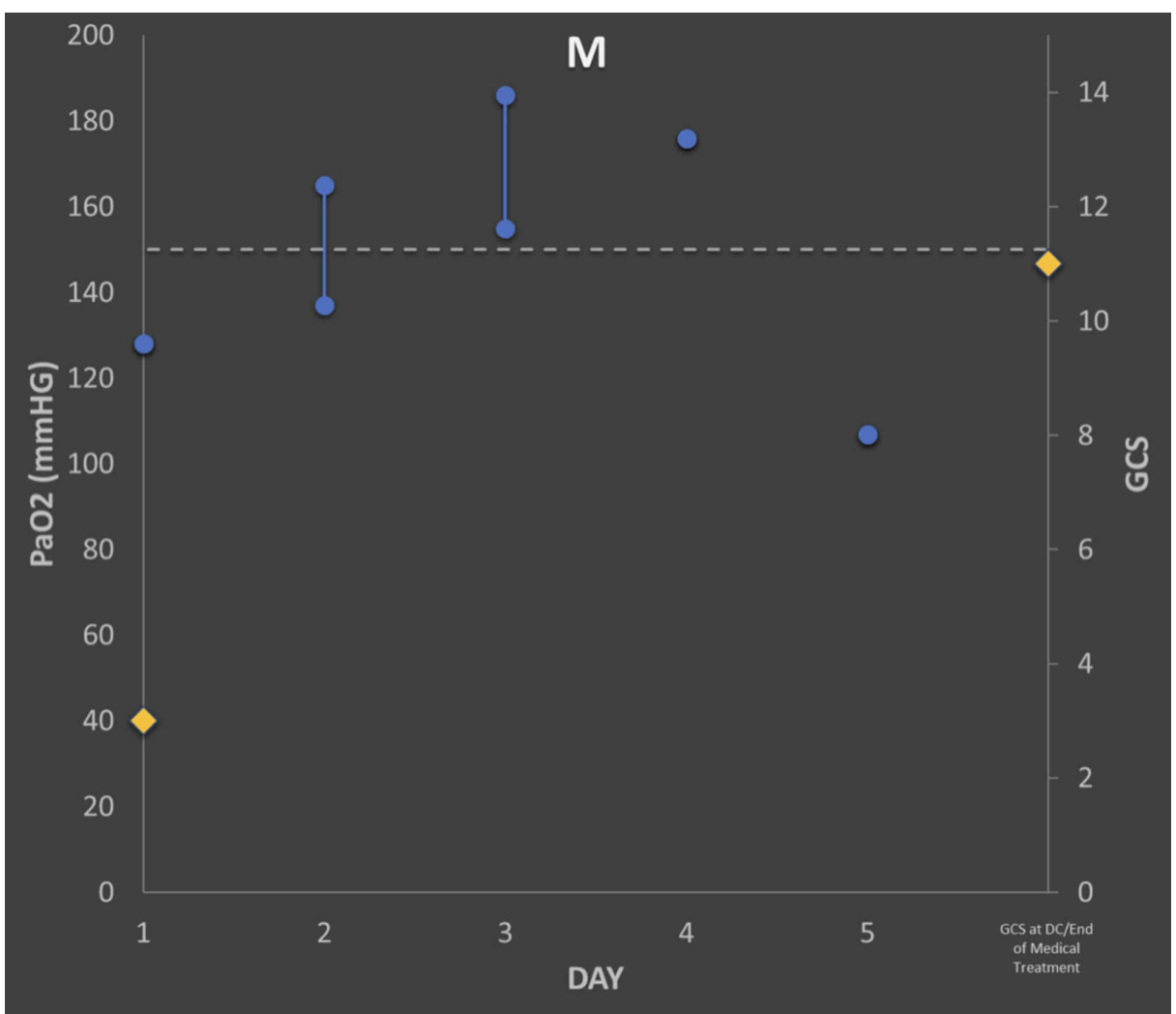

FIGURE 15: Graph for Patient M, demonstrating maximum and minimum $\mathrm{PaO}_{2}$ levels above the predefined $150 \mathrm{mmHg}$ threshold (dotted line)

GCS during the first day of monitoring and at the hospital discharge or the end of ICU-level care are demonstrated by yellow diamonds.

Partial pressure of oxygen ( $\left.\mathrm{PaO}_{2}\right)$; Glasgow Coma Scale (GCS); intensive care unit (ICU).

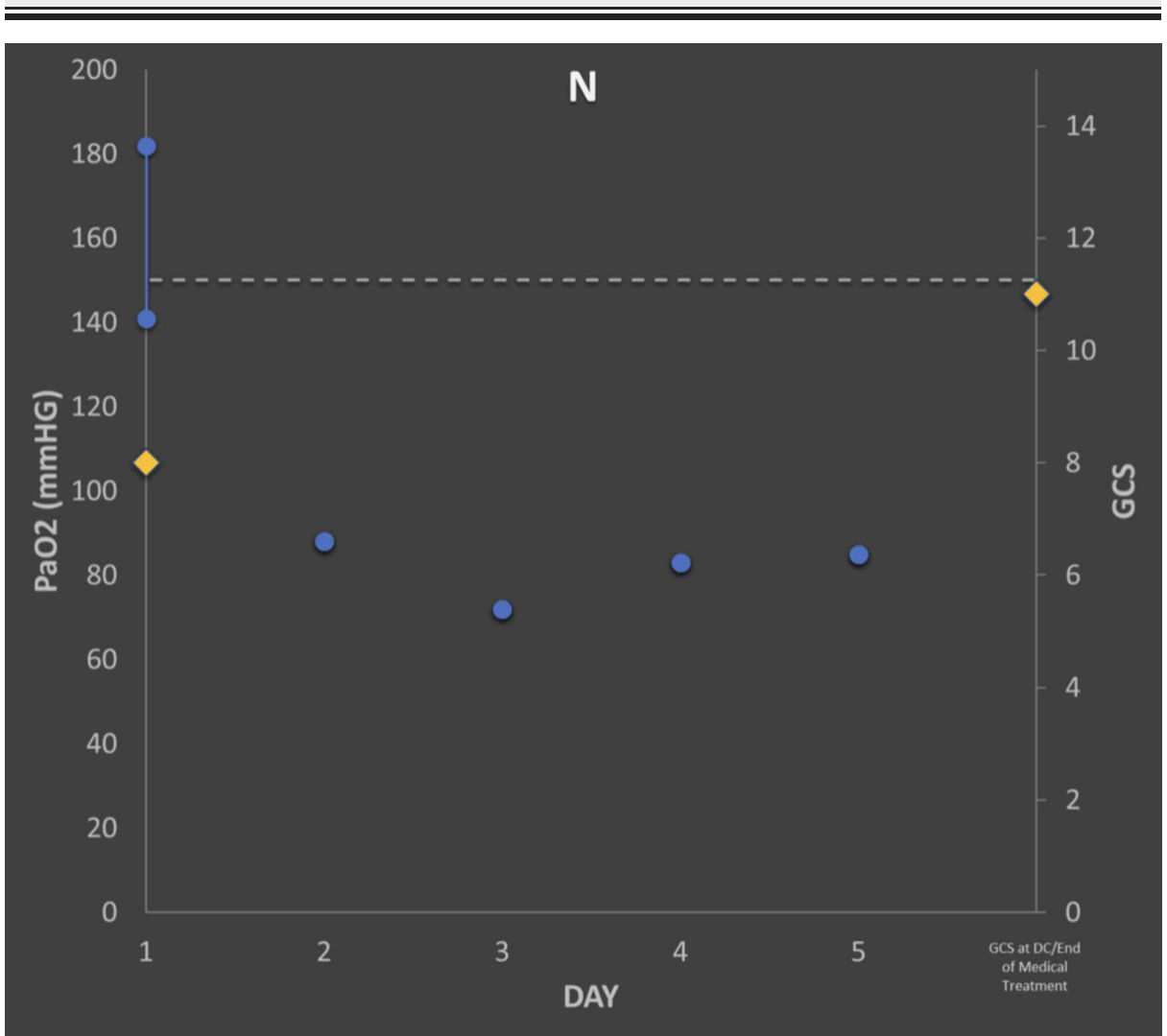




\section{Cureus}

FIGURE 16: Graph for Patient N, demonstrating maximum and minimum $\mathrm{PaO}_{2}$ levels above the predefined $150 \mathrm{mmHg}$ threshold (dotted line)

GCS during the first day of monitoring and at the hospital discharge or the end of ICU-level care are demonstrated by yellow diamonds.

Partial pressure of oxygen ( $\left.\mathrm{PaO}_{2}\right)$; Glasgow Coma Scale (GCS); intensive care unit (ICU).

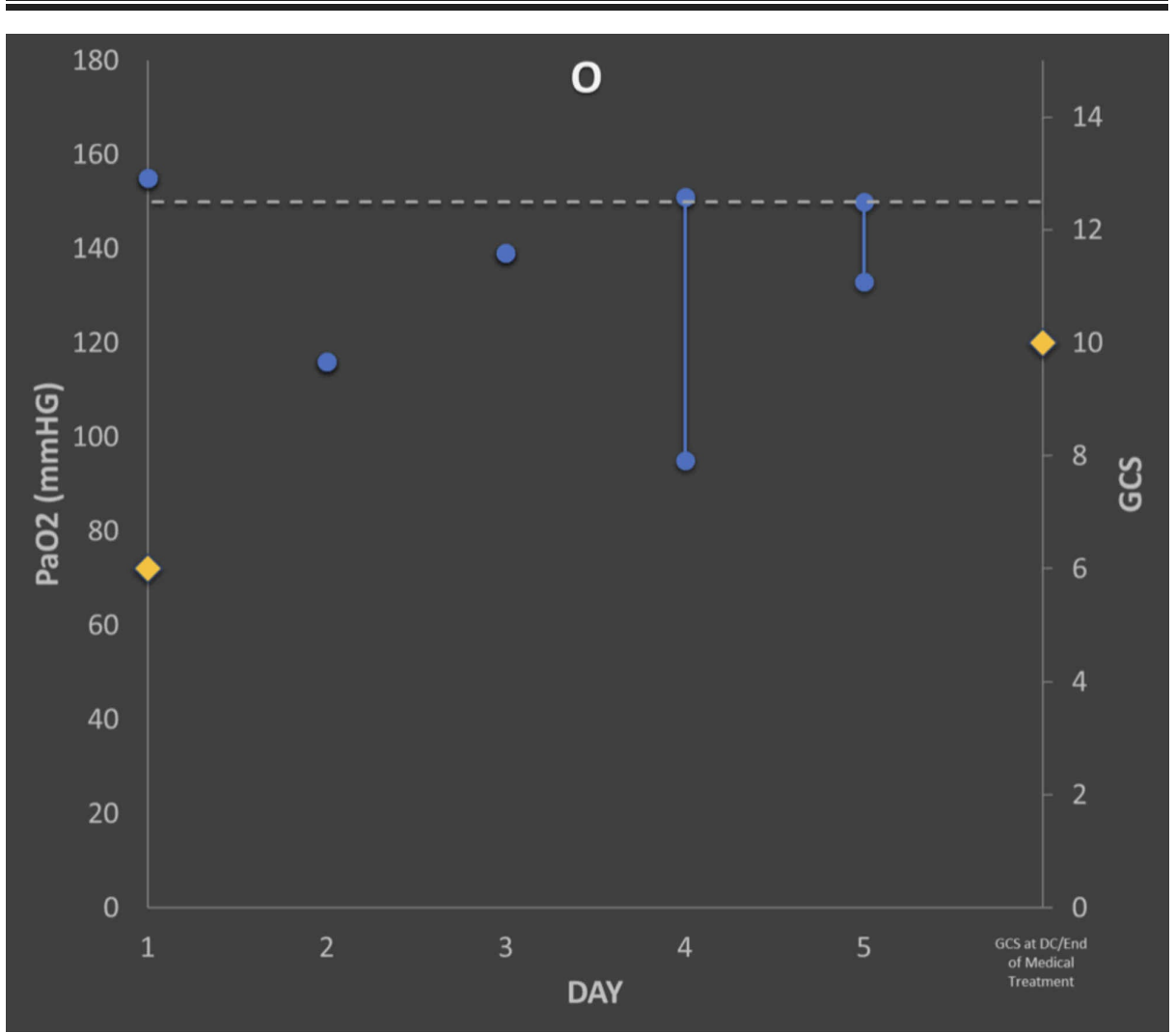

FIGURE 17: Graph for Patient $O$, demonstrating maximum and minimum $\mathrm{PaO}_{2}$ levels above the predefined $150 \mathrm{mmHg}$ threshold (dotted line)

GCS during the first day of monitoring and at the hospital discharge or the end of ICU-level care are demonstrated by yellow diamonds.

Partial pressure of oxygen ( $\left.\mathrm{PaO}_{2}\right)$; Glasgow Coma Scale (GCS); intensive care unit (ICU).

\section{Additional Information}

\section{Disclosures}

Human subjects: Consent was obtained by all participants in this study. Animal subjects: All authors have confirmed that this study did not involve animal subjects or tissue. Conflicts of interest: In compliance with the ICMJE uniform disclosure form, all authors declare the following: Payment/services info: All authors have declared that no financial support was received from any organization for the submitted work. Financial relationships: All authors have declared that they have no financial relationships at present or within the previous three years with any organizations that might have an interest in the submitted work. Other relationships: All authors have declared that there are no other relationships or activities that could appear to have influenced the submitted work.

\section{References}

1. Iaccarino C, Carretta A, Nicolosi F, Morselli C: Epidemiology of severe traumatic brain injury . J Neurosurg Sci. 2018, 10.23736/S0390-5616.18.04532-0

2. Coronado VG, Xu L, Basavaraju SV, et al.: Surveillance for traumatic brain injury-related deaths--United States, 1997-2007. MMWR Surveill Summ. 2011, 60:1-32.

3. Narayan RK, Michel ME, Ansell B, et al.: Clinical trials in head injury. J Neurotrauma. 2002, 19:503-57. 


\section{Cureus}

$10.1089 / 089771502753754037$

4. Corral L, Ventura JL, Herrero JI, et al.: Improvement in GOS and GOSE scores 6 and 12 months after severe traumatic brain injury. Brain Inj. 2007, 21:1225-31. 10.1080/02699050701727460

5. Jiang JY, Gao GY, Li WP, Yu MK, Zhu C: Early indicators of prognosis in 846 cases of severe traumatic brain injury. J Neurotrauma. 2002, 19:869-74. 10.1089/08977150260190456

6. Jennet B, Bond M: Assessment of outcome after severe brain damage: a practical scale . Lancet. 1975, 305:480-484. 10.1016/S0140-6736(75)92830-5

7. Spiotta AM, Stiefel MF, Gracias VH, et al.: Brain tissue oxygen-directed management and outcome in patients with severe traumatic brain injury. J Neurosurg. 2010, 113:571-80. 10.3171/2010.1.JNS09506

8. Enriquez P, Bullock R: Molecular and cellular mechanisms in the pathophysiology of severe head injury . Curr Pharm Des. 2004, 10:2131-43. 10.2174/1381612043384060

9. Davis DP, Meade W, Sise MJ, et al.: Both hypoxemia and extreme hyperoxemia may be detrimental in patients with severe traumatic brain injury. J Neurotrauma. 2009, 26:2217-23. 10.1089/neu.2009.0940

10. Brenner M, Stein D, Hu P, Kufera J, Wooford M, Scalea T: Association between early hyperoxia and worse outcomes after traumatic brain injury. Arch Surg. 2012, 147:1042-6. 10.1001/archsurg.2012.1560

11. Yan EB, Satgunaseelan L, Paul E, et al.: Post-traumatic hypoxia Is associated with prolonged cerebral cytokine production, higher serum biomarker levels, and poor outcome in patients with severe traumatic brain injury. J Neurotrauma. 2014, 31:618-29. 10.1089/neu.2013.3087

12. Bratton SL, Chestnut RM, Ghajar J, et al.: I. Blood pressure and oxygenation. J Neurotrauma. 2007, 24:S7-13. 10.1089/neu.2007.9995 